Çukurova Üniversitesi Mühendislik Mimarlık Fakültesi Dergisi, 35(3), ss. 737-744, Eylül 2020

\title{
Hastelloy C276/UNS S32205 Malzeme Çiftinin Birleștirilmesinde ER 316 L İlave Metal Kullanımının Mikroyapı ve Mekanik Özelliklere Etkisi
}

\author{
Tuba KARAHAN ${ }^{* 1}$ \\ ${ }^{1}$ İstanbul Gedik Üniversitesi, Mühendislik Fakültesi, Metalürji ve Malzeme Mühendisliği \\ Bölümü, Ístanbul
}

Geliş tarihi: 09.09.2020 Kabul tarihi: 23.10 .2020

Öz

Bu çalışmada, Hastelloy C276 nikel bazlı süper alaşım ile UNS S32205 dubleks paslanmaz çelik benzer olmayan malzeme çifti, MAG (metal aktif gaz) yöntemi ve ER 316L ilave metali kullanılarak birleştirilmiştir. Kullanılan ilave metalin kimyasal özellikleri her iki ana malzemenin mekanik ve kimyasal özelliklerinden farklıdır. Kaynaklı bağlantının genel mikro yapısı optik mikroskop ile incelenmiş̧ir. Benzer olmayan birleştirmenin, ergime sınırlarında meydana gelen geçiş bölgesinin elementel karakterizasyonu yapılarak, bu bölgede seyrelme sonucu meydana gelen değişimler elementel haritalama ile açıklanmıştır. İlave metalin Nikel içeriği nedeni ile tüm çentik darbe testi numunelerinde yüksek tokluk değerleri elde edilmiştir.

Anahtar Kelimeler: Ni alaşımları, Dubleks paslanmaz çelik, Kaynak metalürjisi, Mekanik özellikler, Mikroyapı karakterizasyonu

\section{Influence of ER 316 L Filler Metal to Microstructure and Mechanical Properties of Hastelloy C276/UNS 32205 Dissimilar Welds}

\begin{abstract}
In this study, the dissimilar combinations of Hastelloy C-276 nickel-based super alloy and UNS 32205 duplex stainless steel are welded using MAG (metal active gas) method and ER 316L filler metal. The chemical properties of the filler metal are different from the mechanical and chemical properties of both base materials. The general microstructure of the weldment was examined with an optical microscope. The elemental characterization of the transition region between the base metal, weld metal and the fusion line is performed by using elemental mapping and by explaining the elemental mapping in this region with dilution. High toughness results had been obtained because of the nickel content of the filler metal.
\end{abstract}

Keywords: Ni alloy, Duplex stainless steel, Welding metallurgy, Mechanical properties, Microstructural characterization

*Sorumlu yazar (Corresponding author): Tuba KARAHAN, tuba.karahan@gedik.edu.tr 


\section{GíRiș}

Nikel bazlı alaşımlar, yüksek sıcaklıklar da dahil olmak üzere çok çeşitli ortamlar için mühendislikte kullanılan ve korozyona karşı mükemmel dayanım gösteren malzemelerden biridir [1]. Hastelloy C276, nikel bazlı tek fazlı bir süper alaşımdır. Ana alaşım elementleri $\mathrm{Cr}$, Mo, Fe ve W'dır. Alaşım katı çözelti güçlendirmesine dayanarak tasarlanmıştır ve bu alaşımda çökelme sertleşmesi meydana gelmemektedir [2]. Nikel bazlı süper alaşımlar, yüksek korozyon direnci ve yüksek mukavemet nedeniyle kimyasal, petrokimya, havacılık ve nükleer santral vb. çeşitli endüstrilerin gelişiminde önemli bir rol oynamaktadır [3].

Dubleks paslanmaz çelikler yüksek tokluğa ve mekanik mukavemete sahip korozyona dayanıklı alaşımlardır [4]. Dubleks paslanmaz çeliklerin kullanımı, özellikle kimya ve petrokimya endüstrilerinde kullanılan 1sı eşanjörleri ve kimyasal reaktörler gibi sicaklığa duyarlı bileşenlerde, mükemmel mekanik ve korozyon önleme özelliklerinin kombinasyonu sayesinde giderek yaygınlaşmaktadır [5]. Önemli alaşım elementlerinde meydana gelen segregasyonlar korozyon performansinı yerel olarak düşürebilmektedir. Özellikle molibdence zengin çökelmelerin, östenitik yüksek alaşımlı kaynak metallerinin oyuk korozyon direncini azalttığ bilinmektedir [6].

Pahalı bir malzeme olan Hastelloy C276, alaşım maliyetlerini azaltmak için orta riskli koşullarda nispeten düşük fiyatlı paslanmaz çelik malzemeler ile yer değiştirebilir [7]. Bu durum benzer olmayan birleştirmelere olan ilgiyi artırmaktadır. Benzer olmayan birleştirmelerde yapılan kaynak işlemi nikel bazlı süper alaşımlarla ilişkili metalürjik zorlukları beraberinde getirmektedir. Değișken parametreler, seyrelme ve yüksek soğutma hızı nedeniyle, mikro yap1 oldukça karmaşıktır ve bu nedenle mikro yapının tahmin edilmesi zordur [8]. Kimyasal bileşimde mevcut olan farklılı̆̆ yanında, ana metallerin termal genleşme katsayıları da birbirinden farklıdır. Bu ilgili farklılıklar, 1sıdan etkilenen bölgede (ITAB) katılaşma çatlağı, ikincil fazların oluşumu ve karışmamış bölgenin varlığı gibi metalürjik problemlere yol açacaktır. Tüm bu sorunlara rağmen, farklı metallerin birleştirilmesi lokal performans isteyen bölgelerde ekonomik açıdan sağlayacağı avantajlar nedeni ile tercih edilmektedir. Tasarımda esneklik ve performansta iyileşme sağlamaktadır [9].

Farklı iki malzemenin birleştirilmesi ve bunun için en uygun ilave metal seçilmesi kaynak metalinin tokluk özellikleri açısından önemli bir koşuldur. Ayrı iki cins malzemenin birleştirilmesi sonucu elde edilen kaynak dikişi yalnız ilave metalden meydana gelmemektedir, aynı zamanda iki ana malzemeden de önemli miktarda alaşım elementi bulundurmaktadır. Genel olarak kaynak metalinin ana malzemelerin mekanik özelliklerinin üstünde bir performans sergilemesi beklenmektedir. Bu durum benzer olmayan malzemelerin birleştirilmesinde seyrelme ile kaynak metalinin elementel değişime uğramasına ve mikroyapıda çökelmeler oluşmasına neden olmaktadır ve birçok defa kaynak bölgesinin istenmeyen özelliklere sahip olması ile sonuçlanır.

$\mathrm{Bu}$ çalışmanın temel amacı; UNS S32205 dubleks paslanmaz çelik (Dubleks) ile Hastelloy C276 nikel bazlı süper alaşım (Hastelloy) arasındaki birleştirmenin mikroyapılarını ve mekanik özelliklerini araştırmaktır. Bu çalışmada, ER316L ilave metali ile birleştirme işleminde yüksek ergime ve seyreltme gücüne sahip MAG birleștirme yöntemi kullanılmıştır. Elde edilen kaynaklı bağlantı tokluk, mikro yapı elementel karakterizasyon testleri ile incelenerek birleştirmenin uygunluğu test edilmiştir.

\section{DENEYSELÇALIŞMALAR}

Hastelloy ve Dubleks ana metallerin kimyasal içerikleri Çizelge 1'de verilmiştir. İlave metal olarak 1,0 mm çapında, kimyasal kompozisyonu Çizelge 2'de verilen ER 316L ilave metali kullanılmıştır.

Birleştirme MAG kaynak yöntemi ile gerçekleştirilmiştir. Birleştirilen plakaların boyutu $200 \times 100 \times 5 \mathrm{~mm}$ olarak belirlenmiş ve $30^{\circ}$ tek taraflı kaynak ağzı açılarak kaynak işlemine hazırlanmıştır. Seramik altlık ile ve $4 \mathrm{~mm}$ kök 
aralığı bırakılarak elde edilen kaynaklı birleştirmenin şematik gösterimi Şekil 1'de verilmiştir.

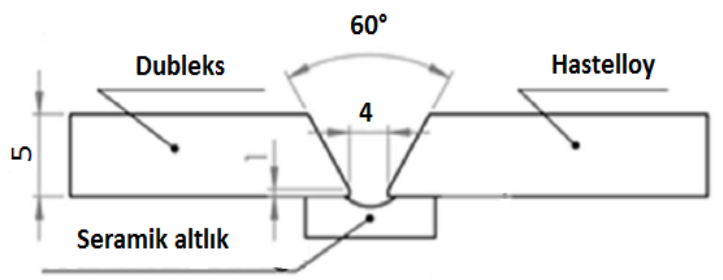

Şekil 1. V-kaynak ağı geometrisine sahip kaynaklı birleştirmenin şematik gösterimi

İki pasolu olarak gerçekleştirilen birleştirmede uygulanan kaynak parametreleri ve 1s1 girdileri Çizelge 3'de verilmiştir. Birleştirme esnasında koruyucu gaz olarak \%98 Argon+\%2 $\mathrm{CO}_{2}$ gazı kullanılmıştır. Kök gazı seramik altlık kullanıldığı için kullanılmamıştır.

Çentik darbe deneyleri oda sicaklığında gerçekleştirilmiştir. Her bir bölge için 3 parça kesilmiş ve daha sonra $5 \times 10 \times 55 \mathrm{~mm}$ boyutunda çentik darbe numuneleri talaşlı işlem ile hazırlanmıştır. Charpy V çentik darbe test numunesi, TS EN ISO 9016 uyarınca kaynak metaline uygulanmış ve TS EN ISO 148-1'e göre test edilmiştir.

Kaynaklı plakalardan elde edilen numuneler mikro yap1 incelemeleri için zımparalama ve parlatma işlemine tabi tutulmuş, \%20 oksalik asit solüsyonunda, $10,5 \mathrm{~V}$ 'da 30 saniye boyunca elektrolitik olarak dağlanmıştır. Kaynak metalinin mikro yapısı optik mikroskop ile incelenmiştir. Metalografik inceleme için hazırlanan numuneler üzerinden sertlik ölçümleri alınmıştır.

Birleştirilen kaynaklı levhanın enine kesitinden çıkarılan numuneler kullanılarak kaynak metalinin elementel kompozisyonu Rigaku - ZSX Primus II $\mathrm{X}$-Ray Spektrometresi ile tespit edilmiştir.

Thermo Scientific ARL OES 8860 marka optik emisyon spektrometresi ile kaynak metalinin ve ana malzemelerin kimyasal içerikleri belirlenmiştir.
Mikro sertlik işlemi, görüntü kontrollü Microbul marka cihaz ile görüntü kontrollü, 10 kgf yük uygulanarak gerçekleştirilmiştir.

Çizelge 1. Ana malzemelerin kimyasal kompozisyonu

\begin{tabular}{|c|c|c|}
\hline Elementler & Hastelloy & Dubleks \\
\hline $\mathrm{Ni}$ & Kalan & 4,85 \\
\hline $\mathrm{Cr}$ & 16,01 & 22,16 \\
\hline $\mathrm{C}$ & 0,004 & 0,02 \\
\hline $\mathrm{Mn}$ & 0,44 & 1,48 \\
\hline $\mathrm{Si}$ & 0,05 & 0,40 \\
\hline $\mathrm{Mo}$ & 15,38 & 3,38 \\
\hline $\mathrm{Fe}$ & 5,8 & 67,29 \\
\hline
\end{tabular}

Çizelge 2. ER316L ilave metali kimyasal kompozisyonu

\begin{tabular}{|c|c|c|}
\hline \multirow{7}{*}{ 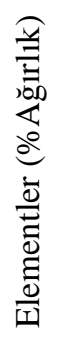 } & $\mathrm{Ni}$ & 11,8 \\
\hline & $\mathrm{Cr}$ & 18,7 \\
\hline & $\mathrm{Mn}$ & 1,7 \\
\hline & $\mathrm{Si}$ & 0,45 \\
\hline & Mo & 2,3 \\
\hline & $\mathrm{C}$ & 0,02 \\
\hline & $\mathrm{Fe}$ & Kalan \\
\hline
\end{tabular}

Çizelge 3. Kaynak parametreleri

\begin{tabular}{|c|c|c|c|c|c|c|}
\hline Paso & \multicolumn{2}{|c|}{ Akım (A) } & \multicolumn{2}{|c|}{ Gerilim (V) } & $\begin{array}{c}\text { Kaynak } \\
\text { hız1 }\end{array}$ & $\begin{array}{c}\text { Is1 } \\
\text { Girdisi } \\
(\mathrm{mm} / \mathrm{s})\end{array}$ \\
\cline { 1 - 4 } Say1s1 & \multicolumn{2}{|c|}{} & & & 1,96 & 1,49 \\
\hline 1 & 113 & 120 & 25,1 & 25,3 & 1,96 \\
\hline 2 & 117 & 123 & 25,2 & 25,3 & 3,23 & 0,94 \\
\hline
\end{tabular}

\section{SONUÇLAR ve TARTIŞMA}

ER 316L ilave metali ile birleştirilen Dubleks ve Hastelloy malzemelerin kaynak metalinin makro yapısı Şekil 2'de verilmiştir. Kesit olarak makro görüntünün alındığı bölgede, çatlak, yetersiz ergime, yanma oluğu vb. hatalar tespit edilmemiştir. Proses parametrelerinin de uygun olduğu görülmektedir. Ayrıca yapılan radyografik muayene sonucu kaynak metalinde yüzey alt1 inklüzyon, gözenek gibi hatalara rastlanmamıştır. 
Hastelloy C276/UNS S32205 Malzeme Çiftinin Birleştirilmesinde ER 316 L İlave Metal Kullanımının Mikroyapı ve Mekanik Özelliklere Etkisi

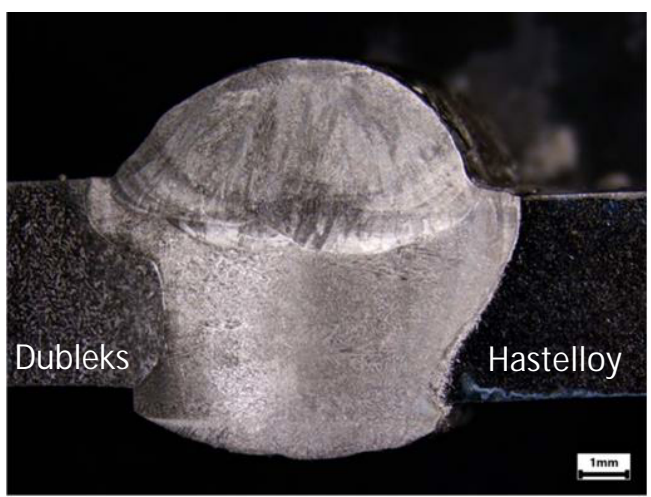

Hastelloy ve Dubleks malzemelere ait mikro yap1 görüntüleri Şekil 3a ve Şekil 3b'de verilmiştir. Hastelloy büyük ostenit taneleri ve tavlama ikizleri içermektedir. Ayrıca mikro yapı içerisinde metalografik işlemler sonucu oluşan oyuklar haricinde yer alan segregasyonlar göze çarpmaktadır. Dubleks malzemenin mikro yapısı granüler ostenit adacıklarına sahip ferrit matristen oluşmaktadır.

Şekil 2. Makro yapı

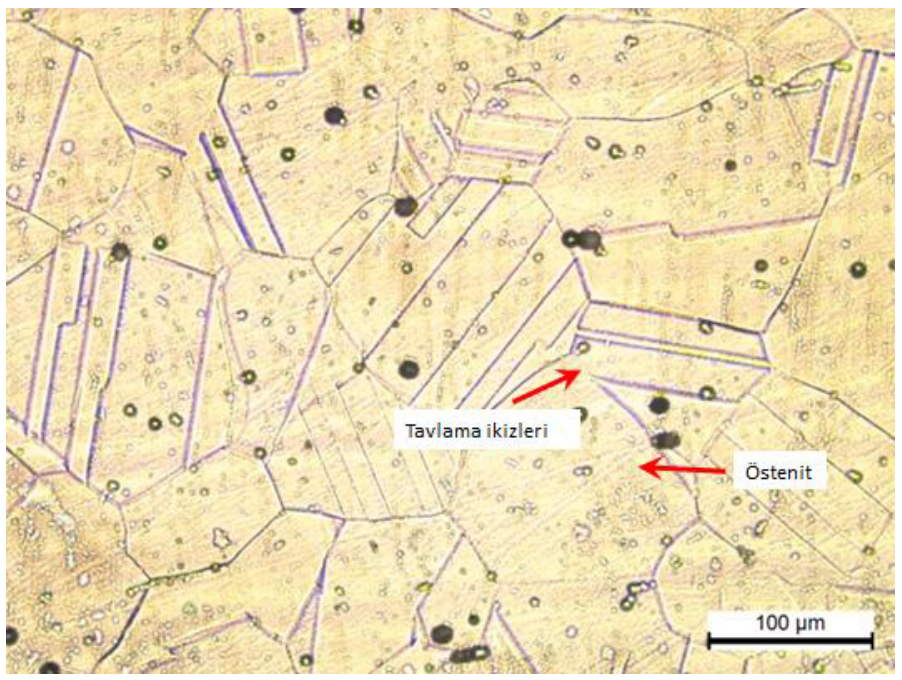

Şekil 3a. Hastelloy C276 mikroyapısı-20x

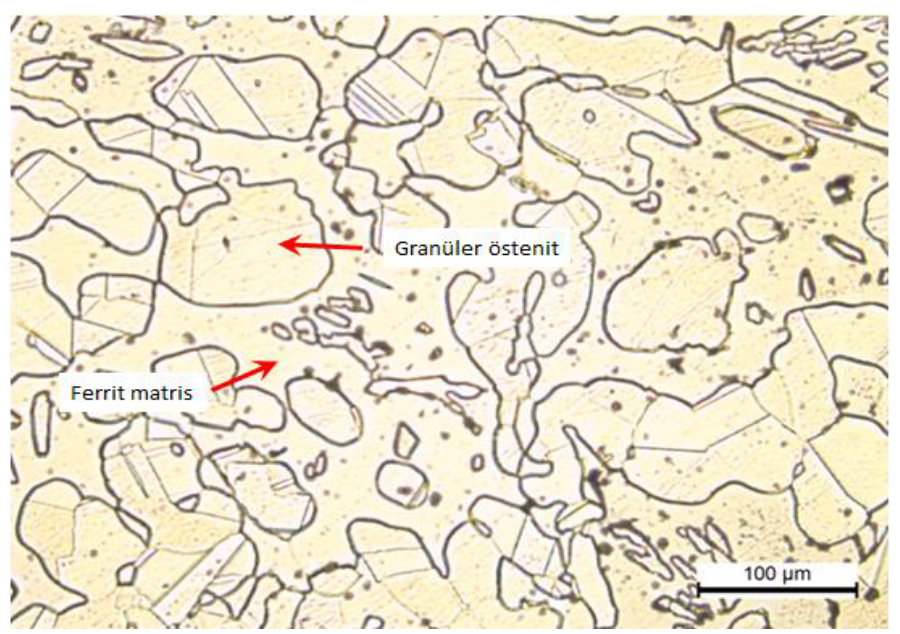

Şekil 3b. Dubleks malzemenin mikroyapısı-20x 
Hastelloy-Dubleks malzeme çiftinin ER316L ilave metal ile birleştirilmesi sonucu elde edilen kaynak metaline yapılan kimyasal analiz sonuçları Çizelge 4'de verilmiştir. Hastelloy malzeme tarafından meydana gelen seyrelme kaynak metali içerisinde nikel ve molibden oranını arttırmıştır.

Çizelge 4 Kaynak metali elementel analizi

\begin{tabular}{|l|c|}
\hline Elementler & Kaynak metali \\
\hline $\mathrm{Ni}$ & 19,89 \\
\hline $\mathrm{Cr}$ & 17,51 \\
\hline $\mathrm{C}$ & 0,02 \\
\hline $\mathrm{Mn}$ & 1,46 \\
\hline $\mathrm{Si}$ & 0,44 \\
\hline $\mathrm{Mo}$ & 5,84 \\
\hline $\mathrm{W}$ & 0,69 \\
\hline $\mathrm{Fe}$ & 53,77 \\
\hline
\end{tabular}

Matris içerisinde yer alan ve kaynak metali mikro yapısında önemli rol oynayan $\mathrm{Ni}, \mathrm{Cr}$, Mo ve $\mathrm{Fe}$ elementlerinin ana malzemeler arasında kaynak metalini de içine alarak oluşturulan elementel haritalama Şekil 4'de verilmiştir. Nikel elementinin ağırlık oranının kaynak metalinin Hastelloy ergime sınırına yakın bölümlerinde \%30'lara kadar yaklaştığı görülmektedir. Kaynak metalinin orta bölgesinde meydana gelen aşırı seyrelme bu bölgede $\mathrm{Ni}$ artışına neden olmuştur. $\mathrm{Bu}$ artış Dubleks malzemeye yaklaştıkça etkisini kaybetmektedir. Kaynak metali içerisinde östenitik paslanmaz çelik ilave metalinin içerdiği $\mathrm{Ni}$ miktarının yaklaşık 1,5 katına çıkan Ni miktarının bu bölgedeki faz yapılarının ve oranlarının değişimine neden olması kaçınılmazdır. $\mathrm{Cr}$ elementi incelenen alan içerisinde diğer elementlere göre daha dengeli bir orantıya sahiptir. Dubleks malzemenin ilave metale göre yüksek olan $\mathrm{Cr}$ oranı ergime sınırı yanında bu elementin oranını arttırmıştır. Kaynak metali içerisindeki intermetalik faz oluşumunda önemli bir görev üstlenen Mo, Hastelloy tarafında meydana gelen seyrelme ile kaynak ilave metalinin içerdiği miktarın yaklaşık iki katına ulaşmıştır. Hastelloy ergime sınırı boyunca, kaynak metali $\sim 11 \%$ civarında Mo içermektedir. Mo miktarı özellikle Hastelloy tipi malzemelerde oluşturduğu intermetalik çökelmeler nedeni ile birçok çalışmaya konu olmuştur [2,3,7,9-12].

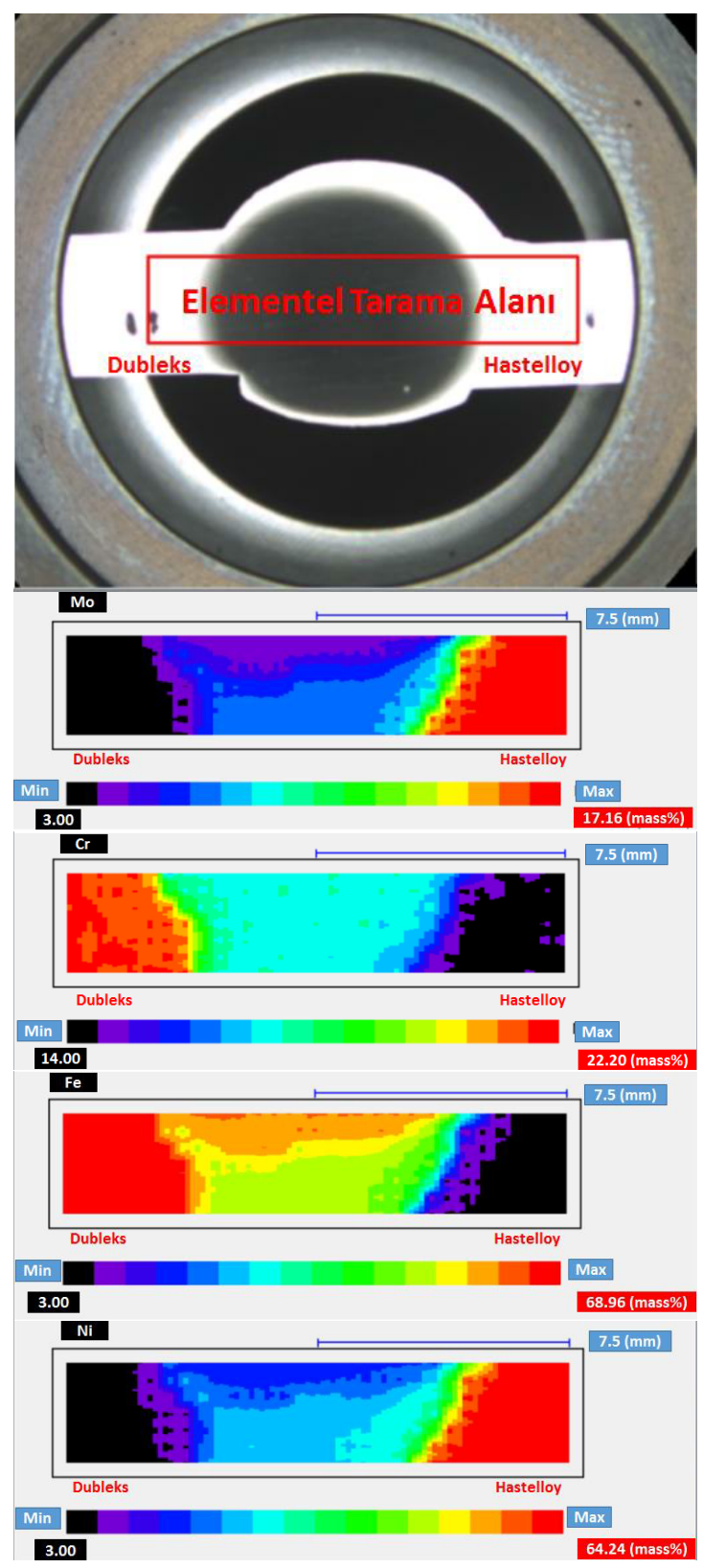

Şekil 4. Elementel haritalama

Klasik ergitme kaynak yöntemlerinde özellikle dendritik kolonsal yapı mikro yapı içerisinde kendine geniş bir alanda yer bulmaktadır. Çok pasolu birleştirmelerde sıcaklık gradyanı nedeni ile bu durum kaynak metalinde belli oranlarda mikro yapısal değişimlere neden olur. $\mathrm{Bu}$ nedenle, daha 
düşük korozyon direncine, mekanik özelliklere ve ayrıca katılaşma çatlağına karşı daha yüksek hassasiyete neden olmaktadır. Kaynak metalinin yapısı genel olarak hücresel, kolonsal dendritler ve eş eksenli dendritlerden oluşmaktadır. Yüksek oranda Ni içeren kaynak metalinin mikro yapısında yer alan ve özellikle dendritler arasında kendine yer bulan intermetalik çökelmelere mikro yapı içinde rastlanmamıştır. Şekil 5a ve 5b'de kaynak metalinin farklı büyütmelerde mikroyapısı görülmektedir.

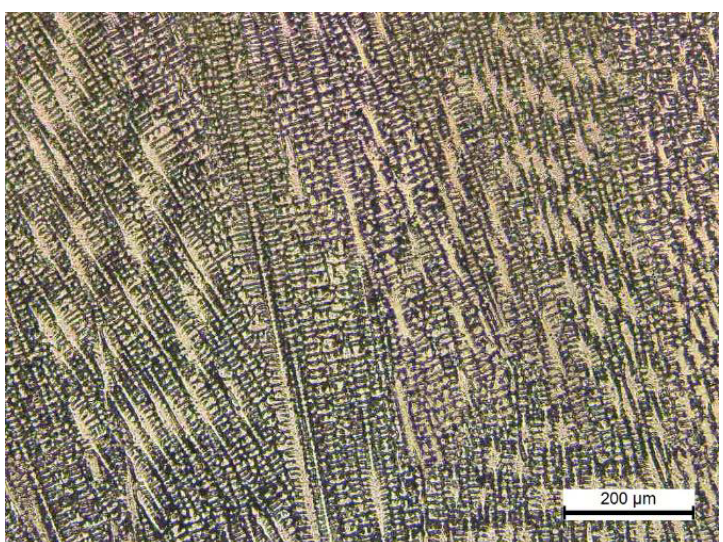

Şekil 5a. Kaynak metali mikro yapısı-10X

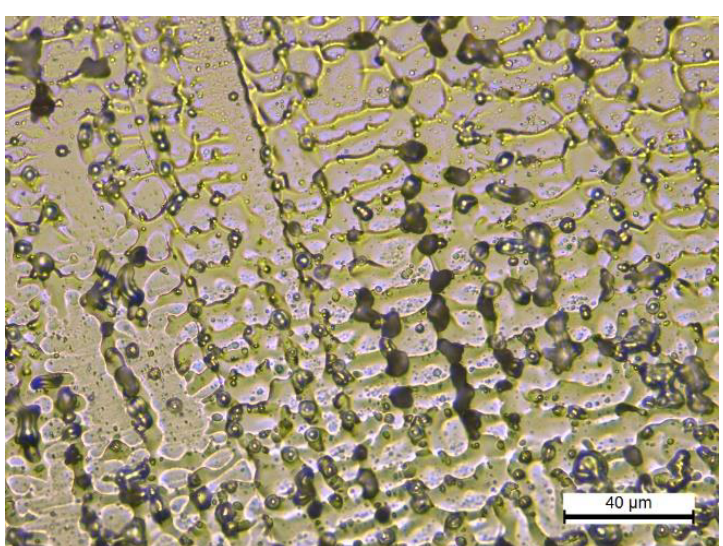

Şekil 5b. Kaynak metali mikro yapısı-50X

Şekil 6a ve 6b'de benzer olmayan ana malzemelerin ergime sınırı ve ITAB bölgelerinden alınan mikro yapıları görülmektedir. Şekil 6a Hastelloy, Şekil 6b ise Dubleks malzemeye ait ergime sınırı ve ITAB bölgesinde meydana gelen değişimleri ortaya koymaktadır. Şekil 6a'da görülen Hastelloy tarafında, kaynak ara yüzeyine bitişik tane sınırı kalınlaşması mevcuttur. Ayrıca benzer olmayan malzeme çiftlerinin kaynak uygulamalarında çok görülen iki farklı kimyasal kompozisyonun oluşturduğu veya kısmen ergimiş bölge (PMZ-Partially Melted Zone) oluşumu mevcuttur. Şekil 6b'de Dubleks tarafında ise tane sınırına dik olarak kolonsal şekilde uzama gösteren östenit taneleri görülmektedir. ITAB bölgesi kısmen büyümüş ferrit matris içerisinde asiküler ve ikincil ostenit taneleri içermektedir.

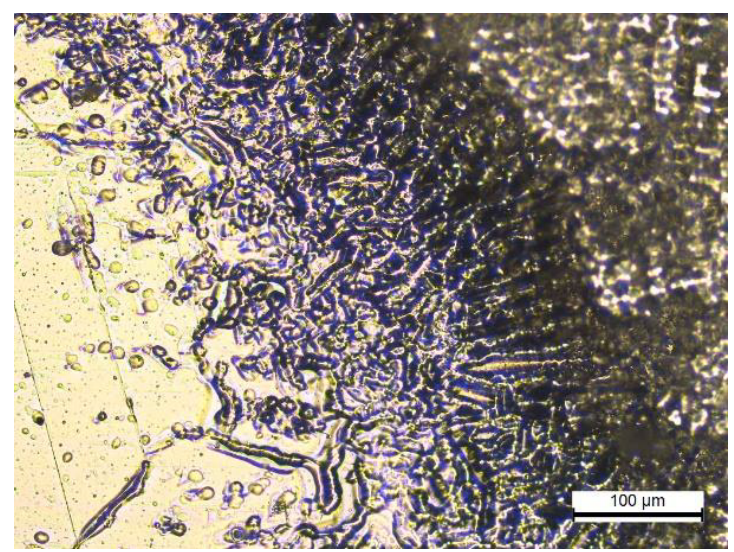

Şekil 6a. Hastelloy ITAB mikro yapısı-20X

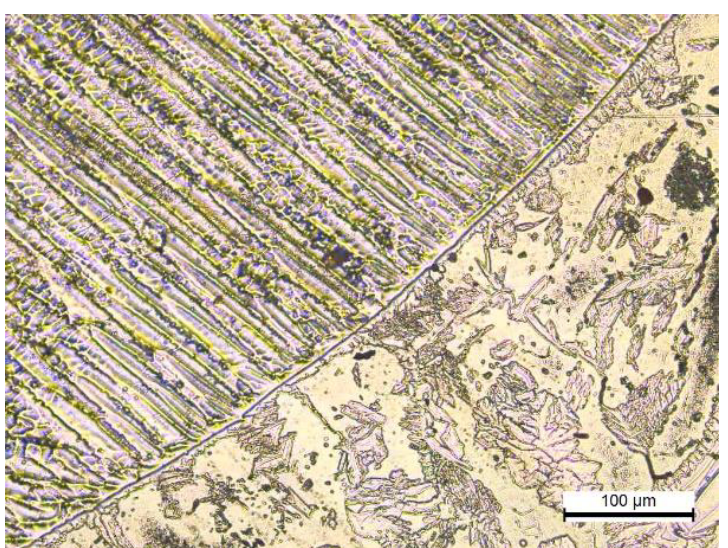

Şekil 6b. Dubleks ITAB mikro yapıs1-20X

ER316L ilave metalinin ana metalden gelen elementlerle modifiye edilen elementel içeriği sayesinde mikro yapıda yüksek 1sı girdisi ile çökelmeler oluşmadığından, birleştirilen parçaların tokluk değerlerine etkisi olmamıştır. Birleştirme esnasında meydana gelen intermetalik fazlar ve 
inklüzyonlar birleștirmenin çentik darbe tokluk değerini düşürebilmektedir. Şekil 7'de kaynak metali ve ana malzemelerin ITAB bölgelerine oda sıcaklığında uygulanan çentik darbe testi sonuçları verilmiştir. Kaynak metaline uygulanan testlerde ortalama 90J çentik darbe enerjisi elde edilmiştir. $\mathrm{Bu}$ değer oda sıcaklığında yüksek miktarda ostenit fazı içeren bir mikro yapı için yeterlidir. Dubleks ITAB ve Hastelloy ITAB bölgelerine uygulanan testlerde elde edilen sonuçlar sırası ile $77 \mathrm{~J}$ ve $75,8 \mathrm{~J}$ olarak gerçekleşmiştir. Elde edilen sonuçlara göre önceki çalışmalarda bahsedilen dubleks ilave metaller ile elde edilen düşük çentik darbe değerleri meydana gelmemiştir $[13,14]$.

$\mathrm{Bu}$ durum intermetalik faz çökelmelerinin oluşmadığı ve sonuçları etkilemediği anlamına gelmektedir.

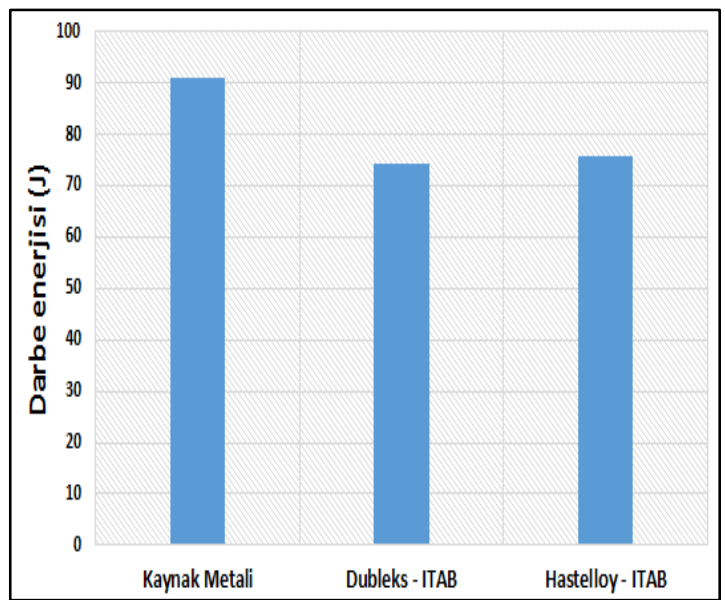

Şekil 7. Darbe enerjileri

Ana malzeme, ITAB ve kaynak metalini takip eden 3 paralel çizgi boyunca, 5 sertlik ölçümü alınmış ve sertlik dağılımı Şekil 8'de makro yapı üzerinde verilmiștir. Dubleks ana malzemenin sertlik değeri $285,3 \pm 4,4$ HV10 iken Dubleks ana malzeme tarafinda yer alan ITAB'da $301,1 \pm 1,4$ HV10, kaynak bölgesinde 353,13 $\pm 13,1$ HV10, Hastelloy ana malzeme tarafındaki ITAB'da $331,3 \pm 16,2$ HV10 ve Hastelloy ana malzemede ise 239 $\pm 2,35$ HV10 sertlik değerleri tespit edilmiştir. Kaynak metalinde kök ve orta pasolarda meydana gelen Mo artışı kaynak metalinde sertlikte bir miktar artışa neden olmuştur.

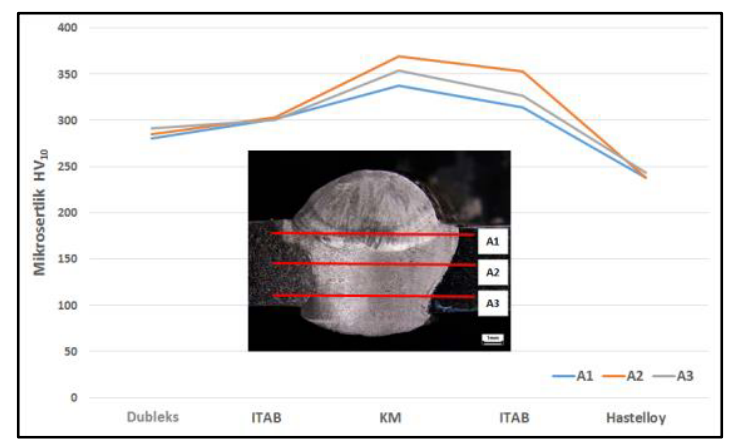

Şekil 8. Kaynaklı birleştirmenin sertlik dağılımı

\section{SONUÇLAR}

Nikel alaşımlarının, paslanmaz çelikler ile birleștirilmesinde genel olarak ERNiCrMo3, ERNiCr3, ERNiCrMo4 gibi nikel alaşımlı ilave metaller önerilmektedir. Bunun yanı sıra Dubleks teller birçok çalışmada denenmiş ve başarısız olmuştur [13-16]. Bu nedenle bu çalışmada kullanılan ER 316L teli, özellikle tokluk açısından yeterli değerleri sağlamıştır. Kaynak metalinin mikro yapısındaki özellikle dendritler arasında beklenen intermetalik faz çökelmelerinin oluşmaması çentik darbe değerlerinin düşmesini engellemiştir. Ancak Hastelloy tarafındaki seyrelme sebebiyle kaynak metalinin $\sim 11 \%$ civarında Mo içermesi kaynak metalinde sertliğin bir miktar artmasına neden olmuştur. Hastelloy C276 ve UNS S32205 dubleks paslanmaz çelikler arasında yapılan birleştirmelerde östenitik ilave metallerin kullanımı düşünülebilir. Fakat seyrelmenin meydana getirdiği yeni kimyasal kompozisyon korozyon açisından değerlendirilmelidir.

\section{TEŞEKKÜR}

Yazar, bu çalışmada kullanılan sarf malzemeler için Gedik Kaynak A.Ş.'ye teşekkürü borç bilir.

\section{KAYNAKLAR}

1. Silva, C.C., Afonso, C.R.M., Ramirez, A.J., Marcelo, F.M., Hélio, C., Jesualdo, P.F., 2016. Assessment of Microstructure of Alloy Inconel 686 Dissimilar Weld Claddings. J Alloys 
Compd 684, 628-642. https://doi.org/10.1016/ j.jallcom.2016.05.231

2. Manikandan, M., Arivazhagan, N., Nageswara, Rao, M., Madhusudhan, R.G., 2015. Improvement of Microstructure and Mechanical Behavior of Gas Tungsten arc Weldments of Alloy C-276 by Current Pulsing. Acta Metall Sin (English Lett 28:208-215. https://doi.org/10.1007/s40195-014-0186-4

3. Sharma, S., Taiwade, R.V., Vashishtha, H., 2017. Effect of Pulsed Current Gas Tungsten Arc Process on the Dissimilar Weldments Between Nickel-based Superalloy/Austenitic Stainless Steel. J Mater Eng Perform 26, 1146-1157. https://doi.org/10.1007/s11665-0172570-5

4. Westin, E.M., Olsson, C.A., Hertzman, S., 2008. Weld Oxide Formation on Lean Duplex Stainless Steel. 50, 2620-2634. https://doi.org/10.1016/j.corsci.2008.06.024

5. Otero, E., Utrilla, M.V., 2007. Weldability of a 2205 Duplex Stainless Steel Using Plasma Arc Welding. 182, 624-631. https://doi.org/10. 1016/j.jmatprotec.2006.08.030

6. Westin, E.M., Hertzman, S., 2014. Element Distribution in Lean Duplex Stainless Steel Welds, 143-160. https://doi.org/10.1007/ s40194-013-0108-5

7. Sharma, S., Taiwade, R.V., Vashishtha, H., 2017. Effect of Continuous and Pulsed Current Gas Tungsten Arc Welding on Dissimilar Weldments Between Hastelloy C-276/AISI 321 Austenitic Stainless Steel. J Mater Eng Perform 26, 1146-1157. https://doi.org/10.1007/ s11665017-2570-5

8. Maltin, C.A., Galloway, A.M., Mweemba, M., 2014. Microstructural Evolution of Inconel 625 and Inconel 686CPT Weld Metal for Clad Carbon Steel Linepipe Joints: A Comparator Study: The Effect of Iron Dilution on the Elemental Segregation of Alloying Elements in Nickel Based Filler Metals. Metall Mater Trans A Phys Metall Mater Sci 45, 3519-3532. https://doi.org/10.1007/s11661-014-2308-z.

9. Ramkumar, K.D., Joshi, V., Pandit, S., Agrawal, M., Oza, S., Periwal, S., Mano, M., Arivazhagan N., 2014. Investigations on the Microstructure and Mechanical Properties of Multi-pass Pulsed Current Gas Tungsten Arc Weldments of Monel
400 and Hastelloy C276. Mater Des 64, 775782. https://doi.org/10. 1016/j.matdes .2014.08.055.

10. Li, G., Huang, J., Wu, Y., 2014. An Investigation on Microstructure and Properties of Dissimilar Welded Inconel 625 and SUS 304 Using High-power $\mathrm{CO}_{2}$ Laser. Int J Adv Manuf Technol 76, 1203-1214. https://doi.org/ 10.1007/s00170-014-6349-7.

11. Madhusudhana, R.G., Srinivasa, M.C.V., Srinivasa, R.K., Prasad, R.K., 2009. Improvement of Mechanical Properties of Inconel 718 Electron Beam Welds-influence of Welding Techniques and Postweld Heat Treatment. Int J Adv Manuf Technol 43, 671680. https://doi.org/10.1007/s00170-008-1751-7.

12. Manikandan, M., Arivazhagan, N., Rao, M.N., Reddy, G.M., 2015. Microstructure and Mechanical Properties of Alloy C-276 Weldments Fabricated by Continuous and Pulsed Current Gas Tungsten Arc Welding Techniques. J Manuf Process 16, 563-572. https://doi.org/10.1016/j.jmapro.2014.08.002.

13. Tumer, M., Karahan, T., Mert, T., 2020. Evaluation of Microstructural and Mechanical Properties of Dissimilar Inconel 625 Nickel Alloy-UNS S32205 Duplex Stainless Steel Weldment Using MIG Welding. Weld World 64, 21-35. https://doi.org/10.1007/s40194-01900825-X.

14. Tümer, M., Mert, T., Karahan, T., 2020. Investigation of Microstructure, Mechanical, and Corrosion Behavior of Nickel-based Alloy 625/duplex Stainless Steel UNS S32205 Dissimilar Weldments Using ERNiCrMo-3 Filler Metal. Weld World. https://doi.org/10.1007/s40194-020-01011-0.

15. Ramkumar, K.D., Oza, S., Periwal, S., Arivazhagan, N., Sridhar, R., Narayanan, S., 2015. Characterization of Weld Strength and Toughness in the Multi-pass Welding of Inconel 625 and Super-duplex Stainless Steel UNS S32750. Cienc e Tecnol dos Mater 27, 41-52. https://doi.org/10.1016/j.ctmat.2015.04. 004.

16. Kangazian, J., Shamanian, M., 2017. Mechanical and Microstructural Evaluation of SAF 2507 and Incoloy 825 Dissimilar Welds. J Manuf Process, 26, 407-418. https://doi.org/ 10.1016/j.jmapro.2017.03.006. 